\title{
VIVÊNCIAS QUE PROMOVEM A SUSTENTABILIDADE: AÇÕES SOCIOEDUCATIVAS AGROECOLÓGICAS
}

\author{
VIEIRA, M.G.M. ${ }^{1 *}$; PRADO, F.H.'; KORZ, C. ${ }^{1}$ \\ 1. Universidade do Vale do Itajaí, Santa Catarina (UNIVALI) \\ 2. Universidade Federal de Santa Catarina (UFSC)
}

*Corresponding author: mmarian@univali.br

\begin{abstract}
Vieira, M.G.M. ${ }^{1}$; Prado , F.H. ${ }^{2}$; Korz, C. ${ }^{1}$ (2020). Assessment of Presidente Getúlio waterfalls bathing conditions - Santa Catarina State, Brazil. Braz. J. Aquat. Sci. Technol. 24(1). elSSN 1983-9057. DOI: 15051/bjast.v24n1. Agroecology is characterized as a form of social inclusion, aiming to sustain the future of the environment from an ecological perspective, with techniques that seek to reduce environmental impacts. The Education for Transformation Extension Project: environment, health and gender, seeks to foster agroecological knowledge and stimulate the transition process to sustainable agriculture through educational research, teaching and extension aimed at strengthening family farming, in addition to targeting the training of academics at the University of Vale do Itajai and the community regarding agroecology. This paper aims to report the formation and experience of the Interdisciplinary Study Group on Agroecology and its contribution to the Sustainable Development Goals (SDGs). The methodology was based on Paulo Freire's Circle of Culture, which enabled continuing education training, with the purpose of promoting health education, environment and gender relations. Through the educational actions promoted by the Project, the participants had the opportunity to interact and dialogue about sustainable agriculture knowledge, promoting the development of the environment in an agroecological way. This was possible thanks to the favorable environment for the exchange of knowledge and experiences with moments of interaction of students with life in the field. It was also possible to contribute to the SDGs, directly in line with goal 12.2 promoting sustainable management and efficient use of natural resources, and 12.8 aimed at ensuring that people have relevant information and awareness for sustainable development and lifestyles in line with nature. From the educational promotion actions the Project provided the autonomy of cultivation of food without the use of chemical inputs, valorization of traditional knowledge and knowledge, health, as well as the construction of a critical and reflective awareness, and most importantly, the longing for changing forms of food production.
\end{abstract}

Key Words: Sustainable agriculture. Environment. Environmental education, Continuing Education.

\section{INTRODUÇÃO}

No início do século XXI houve um rápido desenvolvimento do setor agroalimentar globalizado, corroborando com uma crescente industrialização da agricultura, ambos ancorados em problemas sociais e acesso desigual aos recursos e alimentos, intensificando os efeitos em populações mais vulneráveis Caporal \& Costabeber (2003). Para Méndez \& Espejo (2014), a deterioração nutricional deste modelo, que visa apenas a maximização da produção e do lucro, vai de encontro ao excesso de peso e à obesidade, deixando de lado a melhora da qualidade de vida da população.

Gleissman (2001), afirma que este sistema global agroalimentar está em processo de disseminar sua própria função, gerar alimentos, a qual é alicerçada em técnicas que extraem de forma excessiva os recursos naturais, degradando-os, e isso gera uma dependência de matrizes energéticas não-renováveis.

Em contrapartida, Altieri (2004) traz que a Agroecologia se caracteriza como forma de inclusão social, tornando o camponês o protagonista de seu desenvolvimento, visando sustentar o futuro do meio ambiente, partindo de uma perspectiva ecológica de sintonia entre o ser humano, o agroecossistema e o ambiente, através de práticas que buscam reduzir o impacto socioambiental.

Azevedo \& Pelicioni (2011), reforçam que a agroecologia é como um movimento sociopolítico de fortalecimento do agricultor em busca de sua identidade, raízes culturais, autonomia, poder de decisão e participação ativa no processo produtivo, sendo assim, um sistema economicamente viável, ambientalmente correto e socialmente justo. Por conseguinte, a partir de formas alternativas, procura demonstrar confiança e segurança aos consumidores, resgatando as pre-missas de equidade social; distribuição de riquezas; eliminação das discriminações de gênero ou raça; garantia de direitos a vida, felicidade, saúde, educação, moradia, cultura, emprego e envelhecimento com dignidade; democracia plena, além da responsabilidade ecológica e da participação cidadã como partes indissociáveis do desenvolvimento (Azevedo \& Rigon, 2010).

Segundo Azevedo \& Pelicioni (2011), o modo 
de produzir conhecimento dentro da agroecologia pode ser entendido de acordo com a perspectiva de Paulo Freire e da Educação em Saúde, o qual busca repassar os conhecimentos e expêriencias já acumuladas, tornando o processo de aprendizado participativo.

Com base no que foi acima abordado, em 2015 criou-se o Projeto de Extensão "Educação para Transformação: meio ambiente, saúde e gênero", que trabalha com um grupo de mulheres agricultoras do município de Itajaí, Santa Catarina (SC), auxiliando no processo de transição agroecológica. O Projeto tem o propósito de fomentar saberes agroecológicos através de ações educativas de pesquisa, extensão e ensino, voltadas para o fortalecimento das famílias de agricultores para estimular o processo de transição da agricultura convencional para a agricultura sustentável.

O Projeto também busca integrar a participação de acadêmicos da Universidade do Vale do Itajaí - Univali, a fim de fomentar o conhecimento, o fortalecimento e à consolidação da Agroecologia, os quais privilegiaram a sustentabilidade com enfoque em sistemas produtivos orgânicos.

O Grupo de Estudos Interdisciplinares em Agroecologia (GEIA), criado como um braço do Projeto de Extensão "Educação para Transformação: meio ambiente, saúde e gênero", teve início no primeiro semestre de 2017, vinculado à Univali. Sua proposta partiu da demanda vivenciada por acadêmicos, com o intuito de aprofundar e aplicar os conhecimentos adquiridos dentro da sala de aula, além de promover o conhecimento e o pensamento crítico por meio de estudos aprofundados, pesquisas, debates, e de encontros que abordam temáticas agroecológicas.

Seu propósito foi promover educação continuada em saúde, meio ambiente e relações de gênero para o desenvolvimento social, econômico e ambiental da agricultura familiar, estimulando a participação cidadã como estratégia de mudança, autonomia, promoção de saúde, geração de renda local e estímulo ao consumo de alimentos saudáveis, mediante a agricultura de base agroecológica.

À vista disso, o presente trabalho tem como objetivo descrever as necessidades de incrementar o conhecimento dos acadêmicos sobre agricultura sustentável de base agroecológica, e a sensibilização de uma consciência política sobre a preservação da qualidade ambiental e do equilíbrio ecológico. Além de relatar as contribuições para os Objetivos de Desenvolvimento Sustentável proposto para a Agenda de Desenvolvimento Sustentável da Organização das Nações Unidas - ONU.

\section{MATERIAIS E MÉTODOS}

A metodologia aplicada foi pautada no processo de formação dos participantes e ocorreu por meio da proposta pedagógica de educação continuada, na perspectiva de Paulo Freire. Essa proposta implica o encontro de sujeitos para refletirem sobre sua realidade concreta, denunciando situações conflitantes e anunciando ações que venham a intervir em suas realidades.

Convém ressaltar, que este trabalho foi pautado pela metodologia da pesquisa participante, em razão da preocupação com a participação dos atores sociais envolvidos no processo de pesquisa. Além disso, o referido método requer que o grupo estudado desfrute de uma compreensão satisfatória de sua realidade, participando e tomando posse da construção de conhecimento (Brandão, 1987).

As oficinas e palestras foram realizadas mensalmente, totalizando 120 horas, e ocorreram com a participação dos parceiros do Projeto, convidados pelo grupo, para difundir os conhecimentos sobre a temática abordada, vivenciada em sala de aula, de forma teórica, e, posteriormente, estendendo-se à aplicabilidade da prática de seus encontros na Horta Orgânica Experimental - Ibyporã, criada no início de 2017, com o objetivo de complementar as oficinas teóricas, possibilitando atividades práticas com temáticas discutidas no GEIA.

Esta ação foi proposta inicialmente para os acadêmicos do curso de graduação de Ciências Biológicas, das disciplinas de Química Geral e Química Orgânica, ministradas pela Coordenadora do Projeto, bem como para membros da comunidade, as mulheres agricultoras, professores e outras escolas dos arredores. Atualmente o GEIAé composto por acadêmicos de diversos cursos de graduação e pós-graduação, quais são: Ciências Biológicas, Jornalismo, Direito, Análise Ambiental, Engenharia Ambiental e Sanitária, Engenharia Civil, Oceanografia, Nutrição, Fisioterapia, Gastronomia, Enfermagem, entre outros. Por sua vez, docentes, especialistas, bolsistas, voluntários, membros da comunidade, colaboradores e parceiros do Projeto de Extensão, também fazem parte do Grupo, e além de participarem, auxiliam na realização das oficinas, palestras, seminários e outras estratégias de atuação na área de Agroecologia.

O Projeto de Extensão prevê encontros semanais de formação e planejamento com a equipe extensionista, a qual organiza e sistematiza as informações e registros, gerando dados para o desenvolvimento de pesquisas e relatos de experiências, preparando ações para as oficinas, com o propósito de vivenciar experiências relacionadas às questões ambientais e de sustentabilidade. 
O enfoque nas áreas agroecológicas vem sendo desenvolvido por meio de atividades extensionistas que buscam incentivar o aluno a adentrar em temáticas ambientais recorrentes, estimulando a produção orgânica e o conhecimento teórico-prático trazido de seminários, de práticas na horta orgânica experimental e de saídas de campo.

\section{RESULTADOS E DISCUSSÃO}

As oficinas realizadas pelo Projeto de Extensão Educação para Transformação, a partir do GEIA, trouxeram diferentes temáticas com o intuito de instigar e atrair os alunos para assuntos atuais, de interesse individual e coletivo para a proteção da natureza e da sustentabilidade. A exemplo disso foram abordados temas sobre Plantas Alimentícias Não-Convencionais (PANC), Plantas Medicinais, Sistemas Agroflorestais, Hortas Urbanas, Políticas Públicas de Compostagem, Jardins Produtivos, Segurança e Soberania Alimentar entre outros. Tais ações educativas segundo Freire, proporcionaram aos participantes a oportunidade de interagir e dialogar sobre os saberes da agricultura sustentável, promovendo o desenvolvimento do ambiente de maneira agroecológica.

De acordo com Freire (1983), essas ações educativas têm como foco o encontro de saberes como Círculo de Cultura, abrangendo a "problematização" e a "dialogicidade". Na primeira, proporciona ao sujeito se desprender de sua experiência instantânea e no diálogo crítico com o outro, transcender a consciência ingênua, desenvolvendo sentidos para a sua ação. Já a segunda, pressupõe relações de reciprocidade, com as quais os sujeitos educativos trocam experiências, saberes, necessidades do cotidiano profissional e existencial.

Sob essa ótica, os encontros buscaram estimular a importância do consumo de alimentos orgânicos, alertando sobre os malefícios causados por produtos contaminados pelos agrotóxicos, pelos fertilizantes químicos sintéticos e por outros produtos químicos sintéticos utilizados no modelo de agricultura convencional, além de motivar os participantes a iniciarem suas hortas orgânicas, difundindo o conhecimento à comunidade e promovendo integração entre ensino e extensão.

O modelo agrícola convencional, centrado no uso abusivo de recursos naturais e de agroquímicos de síntese, permitiu aumentar a produção e produtividade de alguns cultivos em certas regiões, mas vem causando forte agressão ao ambiente, sendo insustentável a longo prazo. Ademais, prioriza a produção de commodities e responde mais ao mercado do que às reais necessidades alimentares da população. Esta situação somente poderá ser revertida no momento em que o projeto de desenvolvimento nacional definir o atendimento dos requerimentos alimentares e nutricionais como a principal meta da produção agropecuária, pois existem 44 milhões de brasileiros que não têm atendida sequer sua dieta quantitativa. Contudo, a Segurança Alimentar e Nutricional Sustentável passa pela implementação de estilos de Agricultura Sustentável baseados nos princípios da ciência Agroecologia (Caporal \& Costabeber, 2003).

Apesar das diversas interpretações conceituais que vem tendo nos últimos anos, a Agroecologia corresponde fundamentalmente a um campo de co-nhecimentos de natureza multidisciplinar que pretende contribuir na construção de estilos de agricultura de base ecológica e na elaboração de estratégias de desenvolvimento rural, tendo-se como referência os ideais da sustentabilidade numa perspectiva multidimensional de longo prazo (Caporal \& Costabeber, 2002b). Apenas para citar alguns exemplos, não raramente tem-se confundido a Agroecologia com modelo de agricultura, com processo de produção, com produto ecológico, com prática ou tecnologia agrícola, com política pública, com modo de vida e até com movimento social. Apesar da boa intenção do seu emprego, essas imprecisões podem mascarar a potencialidade que possui o enfoque agroecológico para apoiar o desenvolvimento agrícola e rural (Caporal \& Costabeber, 2002a).

Diante de tal contexto, o GEIA estende a prática de seus encontros à Horta Orgânica Experimental - Ibyporã, promovida e mantida diariamente pelos integrantes do Projeto, local em que os participantes do GEIA podem cultivar, observar e desfrutar de uma melhor compreensão e vivência dos temas e técnicas abordadas e discutidas nas oficinas, estimulando a participação, bem como a inclusão de todos no processo permanente de aprendizagem relacionadas a agroecologia e a educação ambiental possibilitando a compreensão e reflexão sobre a importância destas questões socioambientais e culturais (Figura 1).

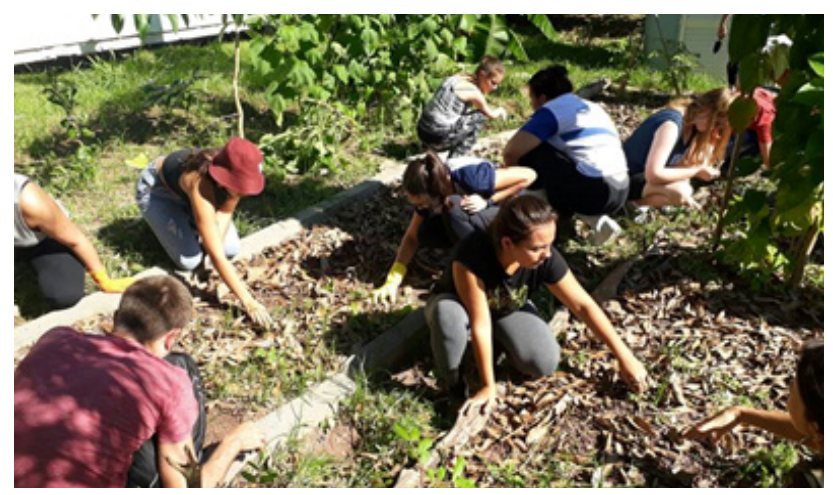

Figura 1 - Oficina prática do GEIA na Horta Orgânica Experimental - lbyporã.

Conforme Wojciechowski (2006), a educação 
ambiental é essencial para debater as questões socioambientais, em virtude da intensificação da degradação do meio natural e social. Nesse sentido, o Projeto teve como propósito potencializar a educação ambiental em todos os níveis de ensino, inclusive a educação da comunidade, objetivando a capacitação para a participação ativa na defesa do meio ambiente e, de forma especial, buscou contribuir para uma consciência política sobre a necessidade de preservação da qualidade ambiental e do equilíbrio ecológico.

Para Bernal (2015), a educação ambiental crítica auxilia na construção de um sujeito cidadão, ecologicamente correto, ao estimular a reflexão sobre decisões relativas aos recursos ambientais. E para que ocorra de forma efetiva, é de suma importância que se incorpore a teoria com a prática, tal estratégia possibilita o despertar de debates, e reflexões críticas acerca das técnicas ecológicas de manejo.

Para a realização da Horta Orgânica Experimental - lbyporã foram elencados temas abrangentes, sendo eles: o manejo adequado do solo, a adubação equilibrada por meio de compostos obtidos pela Compostagem, o controle de pragas e de doenças a partir de herbicidas naturais e, as técnicas de cultivo e colheita. Nesse âmbito, a Horta Orgânica Experimental - Ibyporã proporcionou a interação entre o ensino teórico e prático dos alunos com a Agroecologia, bem como a importância para o meio ambiente e suas relações sociais.

A Horta Orgânica Experimental - Ibyporã é constituída de alimentos sem uso de insumos químicos, produzidos pelas técnicas e práticas de base agroecológica, desde a sua implantação até a sua coIheita, visando projetar agroecossistemas, ao mesmo tempo produtivos, estáveis, equitativos e sustentáveis, primando pela preservação da biodiversidade. Sendo assim, pode-se aliar a aprendizagem, tanto com as práticas proporcionadas pelas oficinas, quanto com o cuidado diário. No início de sua implantação, houve alguns obstáculos, como problemas relacionados à nutrição do solo, infestação de insetos e doenças das plantas cultivadas, porém, com o auxílio dos professores, especialistas e técnicos parceiros do Projeto, foi possível observar um grande progresso com a aplicação das técnicas orientadas por eles, para a estabilização da Horta e do equilíbrio ambiental.

No decorrer do ano 2017, a partir dos conhecimentos adquiridos, os de participantes do Projeto de Extensão, em conjunto com o GEIA, decidiram implantar uma Composteira de Leira. Neste contexto, houve a valorização da fração orgânica atrelada aos princípios da otimização dos resíduos orgânicos gerados nas residências dos participantes do Projeto de Extensão, para a obtenção de compostos orgânicos, por meio da ciclagem de nutrientes, reduzindo assim, a necessi- dade de insumos produzidos a partir de matrizes energéticas não-renováveis. Os resíduos orgânicos foram constituídos, principalmente, por restos de alimentos, bagaços, cascas de frutas, os quais foram usados para abastecimento da Leira. Esse substrato possui concentração adequada de nutrientes necessários para o desenvolvimento das plantas cultivadas nos canteiros da Horta Orgânica Experimental - Ibyporã.

Os resíduos orgânicos, que representam cerca de $50 \%$ dos resíduos urbanos gerados no Brasil, tem a particularidade de poderem ser reciclados por meio de processos como a compostagem, em qualquer escala, desde a doméstica até a industrial. Além dessa abrangência de escalas, a reciclagem de resíduos orgânicos não necessita de grandes exigências tecnológicas ou de equipamentos para que o processo possa ser realizado com segurança, de forma que a compostagem tem tido grande êxito em ações de educação ambiental associadas com jardinagem e agricultura urbana, como forma de empoderar pessoas na reprodução do ciclo da matéria orgânica e mudança de sua visão e relação com resíduos de modo geral (Brasil, 2017).

Atualmente, um dos maiores problemas ambientais mundiais é a destinação final dos resíduos sólidos orgânicos, devido a uma alta taxa crescente de consumo e produção (Pereira, 2011). Diante disso, a compostagem é uma estratégia sustentável e acessível no gerenciamento dos resíduos orgânicos, pois tem como resultado final um produto incapaz de gerar danos ao meio ambiente. Em Florianópolis/SC, foi aprovada a Lei 10.501/2019 que institui a obrigatoriedade da destinação ambientalmente adequada de resíduos sólidos orgânicos por meio dos processos de reciclagem e compostagem (Brasil, 2019).

Ao longo do ano 2017, com a implantação e o estabelecimento da Horta Orgânica Experimental, obteve-se uma elevada produção de alimentos orgânicos, os quais foram colhidos e vendidos nas Feiras de Economia Solidária que ocorrem mensalmente na Univali. Dentre os alimentos produzidos, destacam-se: alface, cebolinha, salsinha, brócolis, couve, rúcula, hortelã, pimenta, tomate-cereja, entre outros alimentos agroecológicos (Figura 2).

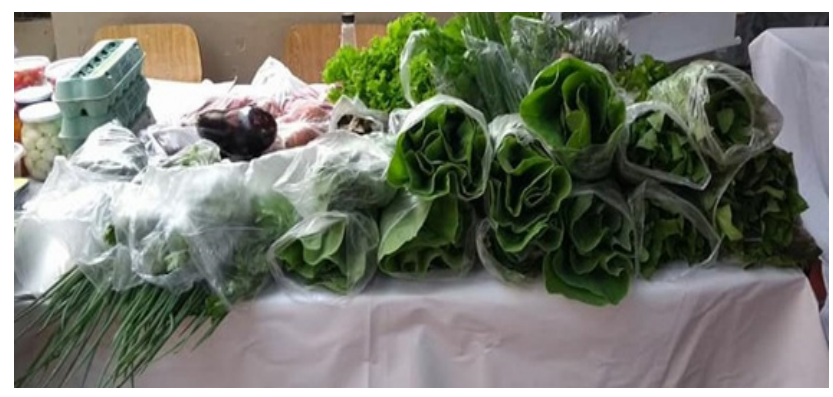

Figura 2 - Alimentos agroecológicos vendidos na Feira Universidade Ecosolidária que ocorre mensamente na Univali. 
A economia solidária é entendida como uma organização socioeconômica, que comercializa produtos de forma mais solidária entre o produtor e consumidor, sendo uma forma de valorizar pequenos produtores, valorizando a mudança social para construção de um novo modelo econômico, visando o bem-estar e não o lucro (Silva, 2016).

Segundo a Universidade do Vale do Itajaí - Univali (2019), a economia solidária pode ser entendida como:

"Uma prática regida pelos valores de autogestão,
democracia, cooperação, solidariedade, respeito à
natureza, promoção da dignidade e valorização do
trabalho humano, no enfrentamento da exclusão
social e da precarização do trabalho, sustentada por
formas coletivas de geração de trabalho e renda."

Aliando-se a todas as iniciativas do GEIA, o Projeto integrou os conhecimentos adquiridos dentro da Universidade com visitas técnicas em propriedades que se caracterizam como modelo de produção agroecológica. Dentre essas ações, os participantes do GEIA tiveram a oportunidade de visitar, em setembro de 2017, o Sítio Flora Bioativas, localizado no município de Porto Belo/SC, com o intuito de estimular os conhecimentos sobre a temática de PANC e Plantas Medicinais cultivadas no Sítio e comercializadas, além de propiciar um ambiente favorável a trocas de saberes e experiências, por meio de roda de conversa, entre estes diferentes atores sociais envolvidos.

Esse encontro proporcionou aos participantes compreender o Sistema de Comunidade que Sustenta o Agricultor (CSA) utilizado na propriedade, o qual busca estimular e incentivar a produção do produtor rural, de forma que o consumidor compre diretamente do produtor. Este sistema consiste na entrega semanal de cestas na residência dos compradores, as cestas são preenchidas por cotas, que contem alimentos como frutas, verduras, leguminosas, hortaliças, PANC, plantas medicinais.

Além da discussão do CSA, nesta visita técnica foi possível destacar algumas plantas de maior valor econômico e nutracêuticas, enfatizando a importância, benefícios e formas de usar de algumas espécies, como: Tupinambor (Helianthus tuberosus L.), Orapro-nobis (Pereskia aculeata Mill.), Moringa (Moringa oleifera Lam.), Jambu (Spilanthes acmella (L.) L.); Zedoária (Curcuma zedoaria (Christm.) Roscoe), e outras espécies cultivadas na propriedade.

A troca de informações entre os proprietários e os acadêmicos foi vantajosa para ambos os lados, os alunos viram a realidade do sítio e tomaram como uma inspiração de um modelo ideal e aplicável, no qual há uma grande variedade de produtos cultivados que são administrados por poucas pessoas. Além de mostrar aos participantes a influência das plantas para a obtenção de cura, redução de sintomas patológicos e prevenção de doenças, de modo a reduzir a necessidade de consumo de medicamentos constante. Com isso muitos dos participantes relataram que após a visita passaram a consumir as plantas conhecidas no Sítio Flora Bioativas, bem como plantas que possuem um manejo ecológico e sustentável, o que possibilitou ao Projeto concluir que a visita teve influência positiva em suas vidas. Já para o sítio foi possível divulgar o trabalho que vem sendo realizado e conquistar novos co-produtores para o CSA.

Com as ações desenvolvidas pelo Projeto espera-se que os acadêmicos usufruam delas para elevar e complementar seus conceitos a respeito das temáticas trabalhadas, para que sejam multiplicadores, tanto na vida acadêmica quanto na vida pessoal, dos conhecimentos adquiridos. A partir das atividades exercidas, os acadêmicos puderam aprofundar os conhecimentos quanto à temática da Agroecologia, do desenvolvimento sustentável, do desempenho ambiental, da educação ambiental, da valorização das mulheres no campo, de saberes tradicionais e da fração orgânica, bem como da promoção de saúde, da soberania alimentar, da construção de uma consciência crítica em relação aos fatores envolvidos nos processos da agricultura e suas relações com o desenvolvimento da sociedade. Após a realização das vivências, percebeu-se que diversos alunos têm interesse nesses temas; no entanto, convém lembrar, que é imprescindível para eles, enquanto futuros profissionais, conhecer o quão complexo são os temas abordados, a fim de lutarem para preservar cada vez mais a natureza que vem sendo duramente degradada.

A acadêmica G. O. S. destaca que:

"Nós, acadêmicos, também não enxergávamos na
prática como funcionaria esta agricultura sustentável, e a
diferença de alimentos orgânicos para os convencionais
com agrotóxicos. Mas foi na saída de campo que tivemos a
oportunidade de provar o suco orgânico e morangos diretos
da plantação, percebendo a total diferença deste para os
que compramos em supermercados, e vendo que vale a
pena investir em alimentos orgânicos, que além de mais
saudáveis possuem uma qualidade em sabor muito maior."

Para a vida acadêmica, é de suma importância a participação em eventos científicos, uma vez que é por meio destes que ocorre o desenvolvimento da formação dos acadêmicos, agregando saberes, os quais são fatores determinantes para o desenvolvimento profissional e pessoal.

Neste sentido, o estímulo à participação dos alunos em eventos científicos, como o IX Fórum Brasileiro de Educação Ambiental - IX FBEA e o IV Encontro 
Catarinense de EA - IV ECEA, teve como propósito, além da construção de uma visão holística, a formação de uma reflexão crítica sobre os assuntos correlatos.

A acadêmica C. B. V. caracteriza a participação em eventos como:

\begin{abstract}
"A conscientização por meio destes eventos leva à mudança individual, e conseguimos enxergar muitos jovens possuindo esta conscientização e levando-as à sua família e aos seus amigos. Muitas vezes, mesmo sem condições para consumir integralmente produtos orgânicos, os jovens começam comprando aos poucos, ou até criando uma pequena horta em sua casa ou apartamento, o que já contribui enormemente para a diminuição de produtos ricos em venenos."
\end{abstract}

As vivências proporcionadas pelo Projeto de Extensão com o púbico alvo contribuíram com os Objetivos de Desenvolvimento Sustentável (ODS), propostos pela Organização das Nações Unidas - ONU para a Agenda de 2030. De forma direta foi possível contribuir com o ODS 12 que visa Assegurar padrões de produção e de consumo sustentáveis, onde contribui com as metas 12.2 promover gestão sustentável e uso eficiente de recursos naturais, e 12.8 que visa garantir que as pessoas tenham informações relevantes e conscientização para o desenvolvimento sustentável e estilos de vida em sintonia com a natureza.

Dentro de suas ações de sustentabilidade é possível afirmar que contribuir com tais metas devido a capacitação realizada com diversos púbicos, desde o meio acadêmico até o meio rural, modificando a forma de pensar e agir dos envolvidos com o Projeto e os tornando multiplicadores de saberes no meio em que estão inseridos.

\section{CONCLUSÕES}

No decorrer das ações e atividades do Projeto de Extensão "Educação para Transformação: meio ambiente, saúde e gênero", compreendeu-se a articulação entre vários atores da sociedade, entre eles, os acadêmicos, os professores, os agricultores, a Secretaria do Meio Ambiente, a Universidade, entre outros. Tais articulações são fundamentais para o êxito das ações coletivas, com o propósito de impactar uma ampla gama de envolvidos, aprimorando os conhecimentos técnicos profissionais e pessoais, gerando assim, diretrizes para fomentar a emancipação e a autonomia dos indivíduos, a valorização e a troca de saberes tradicionais, a participação política para o desenvolvimento social, econômico e ambiental, além de gerar uma mobilização social, propiciando aos participantes maior índice de qualidade de vida.

Sendo assim, apresentam-se como elementos essenciais a articulação de saberes técnicos e populares, bem como a mobilização de recursos institucionais e comunitários para o enfrentamento e resolução como modelo de contraposição dos problemas ambientais, sociais e econômicos.

Neste contexto, as estratégias das iniciativas são capazes de disseminar os saberes e apoiar os processos de redução das desigualdades e das iniquidades sociais, pela participação ativa dos sujeitos na construção de processos educacionais, aliando a teoria vivenciada dentro das salas de aula com a prática, em um ambiente externo, o mais próximo da realidade.

Vale ressaltar, a importância destas iniciativas de grupos de projetos que visam promover ações educativas para fomentar os conhecimentos da defesa ativa do ambiente. Com esta ação, o Projeto ampliou as fronteiras entre a Universidade e a comunidade, trazendo soluções diárias para a vida da população, fortalecendo estes elos entre a teoria científica e a aplicação das práticas. Além disso, os relatos dos participantes têm fortalecido a ampliação do Projeto, o que propicia o maior acesso à população e traz benefícios a toda a sociedade. Segundo os participantes, o Projeto tem proporcionado uma mudança na qualidade de vida, a inclusão destes atores nos processos, a autonomia de produção, o cultivo de alimentos sem uso de insumos químicos, a valorização dos conhecimentos e saberes tradicionais, a valorização da fração orgânica, a saúde, o bem-estar, bem como a construção de uma consciência crítica e reflexiva frente a diversos temas, e o mais importante, o anseio pela mudança das formas de produção de alimentos.

\section{REFERÊNCIAS}

ALTIERI, M. 2004. Agroecologia: a dinâmica produtiva da agricultura sustentável. $5^{\mathrm{a}}$ Edição. UFRGS, Porto Alegre, 117p. Disponível: https://www.socla. co/wp-content/uploads/2014/Agroecologia-AltieriPortugues.pdf. Acessado em 23 jul 2019.

AZEVEDO, E. \& PELICIONI, M. C. F. 2011. Promoção da Saúde, Sustentabilidade e Agroecologia: uma discussão intersetorial. São Paulo: Saúde Soc., 20(3): 715-729. Disponível em: https://www. scielosp.org/article/sausoc/2011.v20n3/715-729/. Acessado em: out. 2017.

AZEVEDO, E. \& RIGON, S. A. 2010. Sistema alimentar com base no conceito de sustentabilidade. Rio de Janeiro: Editora Rubio, Rio de Janeiro, 664p.

BERNAL, A. B. (Org.). 2015. Apoio à Implementação do Programa de Educação Ambiental e Agricultura Familiar nos Territórios. Volume 1. MMA, Brasília, $68 p$.

BRANDÃO, C. R. 1987. Repensando a pesquisa participante. $3^{\circ}$ Edição. Brasiliense, São Paulo, 252p. 
BRASIL. Lei Federal $n^{\circ} 12.305$ de 02 de agosto de 2010: Institui a Política Nacional de Resíduos Sólidos; altera a Lei n. 9.605, de 12 de fevereiro de 1998; e dá outras providências. Brasília, 2010. Disponível em: <http://www.planalto.gov. br/ccivil_03/_ato2007-2010/2010/lei/l12305.htm>. Acesso em: out. 2017.

BRASIL. 2019. Lei Municipal n 10.501: Dispões sobre a obrigatoriedade da reciclagem de resíduos sólidos orgânicos no munícipio de Florianópolis, de 08 de abril de 2019. Florianópolis, 2019. Disponível em: <https://leismunicipais.com.br/a1/ sc/f/florianopolis/lei-ordinaria/2019/1051/10501/ lei-ordinaria-n-10501-2019-dispoe-sobre-aobrigatoriedade-da-reciclagem-de-residuossolidos-organicos-no-municipio-de-florianopolis>. Acesso em: out. 2017.

BRASIL. 2017. Compostagem Doméstica, Comunitária e Institucional de Resíduos Orgânicos: manual de orientação. Brasília: Ministério do Meio Ambiente/ Cepagro, 68p. Disponível em: <http://arquivos. ambiente.sp.gov.br/municipioverdeazul/2016/07/ rs6-compostagem-manualorientacao_mma_201706-20.pdf>. Acesso em: out. 2017.

CAPORAL, F. R.; COSTABEBER, J. A. 2002a. Agroecologia: enfoque científico e estratégico. Porto Alegre: Agroecologia e Desenvolvimento Rural Sustentável, v.3, n.2, p.13-16. Disponível em: $<$ https://www.asbraer.org.br/index.php/consulta/ item/download/160_5a998f0d0a64fb0c7b813e4c 17cb2167>. Acessado em: 29 out. 2019.

CAPORAL, F. R.; COSTABEBER, J. A. 2002b. Análise multidimensional da sustentabilidade: uma proposta metodológica a partir da Agroecologia. Porto Alegre: Agroecologia e Desenvolvimento Rural Sustentável, v.3, n.3, p.70-85. Disponível em: <reformaagrariaemdados.org.br/sites/default/ files/Analise $\% 20$ multidimensional $\% 20 \mathrm{da} \% 20$ sustentabilidade, $\% 20$ uma $\% 20$ proposta $\% 20$ metodologica $\% 20$ a $\% 20$ partir $\% 20$ da $\% 20$ agroecologia\%20-\%20Francisco\%20Caporal,\%20Jose\%20Costabeber.pdf>. Acessado em: 29 out. 2019.

CAPORAL, F. R.; COSTABEBER J. A. 2003. Segurança alimentar e agricultura sustentável: uma perspectiva agroecológica. Santa Maria: Ciência \& Ambiente, v. 14, n.27, p.153-165. Disponível em: <http://www.mobilizadores.org.br/ wp-content/uploads/2014/05/segurana-alimentare-agricultura-sustentvel.pdf>. Acessado em: 29 out. 2019.

FREIRE, P. 1983. Pedagogia do oprimido. $12^{\circ}$ Edição. Paz e Terra, Rio de Janeiro, 256p.
GLEISSMAN, S. R. 2001. Agroecologia: processos ecológicos em agricultura sustentável. $4^{\circ}$ Edição. UFRGS Editora, Rio Grande do Sul, 653p.

MÉNDEZ, C. D. \& ESPEJO, I. G. La mirada sociológica hacia a alimentación: análisis crítico del desarrollo de la investigación en el campo alimentario. 2014. Madrid: Política y Sociedad, n. 51, p. 15-49. Disponível em: https://revistas.ucm.es/index.php/ POSO/article/view/42472/42442. Acessado em: out. 2017.

NAÇÕES UNIDAS BRASIL. A Agenda 2030. 2015. Disponível em: <https://nacoesunidas.org/ pos2015/ods12/>. Acessado em: out. 2017.

PEREIRA, S. S. 2011. A problemática dos resíduos sólidos urbanos e os instrumentos de gestão do meio ambiente na cidade de Campina Grande/PB. São Paulo: Âmbito Jurídico, v.93. Disponível em: $<$ https://ambitojuridico.com.br/cadernos/direitoambiental/a-problematica-dos-residuos-solidosurbanos-e-os-instrumentos-de-gestao-do-meioambiente-na-cidade-de-campina-grande-pb/>. Acessado em: out. 2017.

SILVA, F. R. F. 2016. Gênero, agroecologia e economia solidária: estudo de caso do grupo de mulheres do Acampamento Recanto da Natureza em Laranjeiras do Sul - PR. Paraná: Desenvolv. Meio Ambiente, v.39, p.115-132. Disponível em: <https:// revistas.ufpr.br/made/article/view/45697/30130>. Acessado em: 29 out. 2019.

UNIVERSIDADE DO VALE DO ITAJAÍ. 2019. Incubadora Tecnológica de Cooperativas Populares Univali - ITCP. Itajaí. Disponível em: <https://www.univali.br/institucional/ vice-reitoria-planejamento-desenvolvimentoinstitucional/extensao/incubadora-tecnologica-decooperativas-populares-da-univali-itcp/Paginas/ default.aspx>. Acessado em: 10 abr. 2019.

WOJCIECHOWSKI, T. 2006. Projetos de Educação Ambiental no Primeiro e no Segundo Ciclo do Ensino Fundamental: Problemas Socioambientais no Entorno de Escolas Municipais de Curitiba. Dissertação Programa de Pós-Graduação em Educação - Setor de Educação da Universidade Federal do Paraná: Curitiba. 173p. Disponível em http://www.ppge.ufpr.br/teses/M06_wojciechowski. pdf. Acessado em nov. 2017.

Submetido: Agosto/19 Revisado: Dezembro/19 Aceito: Dezembro/19 Publicado: 17/04/2020 